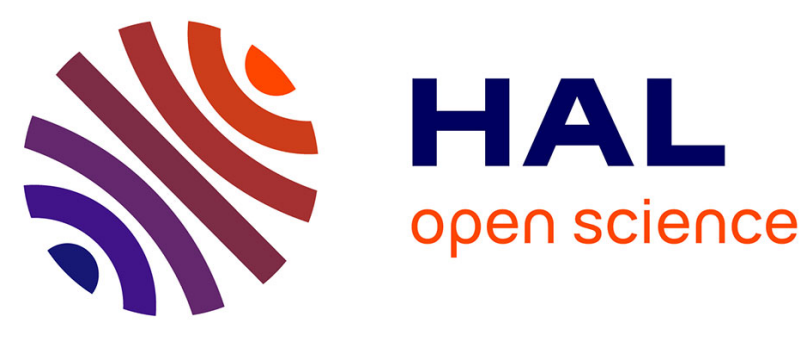

\title{
Disentangling Chromophore States in a Reversibly Switchable Green Fluorescent Protein: Mechanistic Insights from NMR Spectroscopy
}

Nina Eleni Christou, Karine Giandoreggio-Barranco, Isabel Ayala, Oleksandr Glushonkov, Virgile Adam, Dominique Bourgeois, Bernhard Brutscher

\section{To cite this version:}

Nina Eleni Christou, Karine Giandoreggio-Barranco, Isabel Ayala, Oleksandr Glushonkov, Virgile Adam, et al.. Disentangling Chromophore States in a Reversibly Switchable Green Fluorescent Protein: Mechanistic Insights from NMR Spectroscopy. Journal of the American Chemical Society, 2021, 143 (19), pp.7521-7530. 10.1021/jacs.1c02442 . hal-03328569

\section{HAL Id: hal-03328569 \\ https://hal.univ-grenoble-alpes.fr/hal-03328569}

Submitted on 30 Aug 2021

HAL is a multi-disciplinary open access archive for the deposit and dissemination of scientific research documents, whether they are published or not. The documents may come from teaching and research institutions in France or abroad, or from public or private research centers.
L'archive ouverte pluridisciplinaire HAL, est destinée au dépôt et à la diffusion de documents scientifiques de niveau recherche, publiés ou non, émanant des établissements d'enseignement et de recherche français ou étrangers, des laboratoires publics ou privés. 


\title{
Disentangling Chromophore States in a Reversibly Switchable Green Flu- orescent Protein: Mechanistic Insights from NMR Spectroscopy
}

\author{
Nina Eleni Christou, Karine Giandoreggio-Barranco, Isabel Ayala, Oleksandr Glushonkov, Virgile Adam, \\ Dominique Bourgeois, Bernhard Brutscher* \\ Université Grenoble Alpes, CEA, CNRS, Institut de Biologie Structurale (IBS), 71 avenue des Martyrs, 38044 Grenoble Cedex 9, \\ France
}

Supporting Information Placeholder

ABSTRACT: The photophysical properties of fluorescent proteins, including phototransformable variants used in advanced microscopy applications, are influenced by the environmental conditions in which they are expressed and used. Rational design of improved fluorescent protein markers requires a better understanding of these environmental effects. We demonstrate here that solution NMR spectroscopy can detect subtle changes in the chemical structure, conformation, and dynamics of the photoactive chromophore moiety with atomic resolution, providing such mechanistic information. Studying rsFolder, a reversibly switchable green fluorescent protein, we have identified 4 distinct configurations of its $p$-HBI chromophore, corresponding to the cis and trans isomers, with each one either protonated (neutral) or deprotonated (anionic) at the benzylidene ring. The relative populations and interconversion kinetics of these chromophore species depend on sample $\mathrm{pH}$ and buffer composition that alter in a complex way the strength of $\mathrm{H}$-bonds that contribute in stabilizing the chromophore within the protein scaffold. We show in particular the important role of histidine-149 in stabilizing the neutral trans-chromophore at intermediate $\mathrm{pH}$ values, leading to ground-state cis-trans isomerization with a peculiar $\mathrm{pH}$-dependence. We discuss the potential implications of our findings on the $\mathrm{pH}$-dependence of the photoswitching contrast, a critical parameter in nanoscopy applications.

\section{INTRODUCTION}

Phototransformable fluorescent proteins (PTFPs) change their fluorescent state upon illumination at specific wavelengths and are thus crucial for a wide range of applications in advanced fluorescence microscopy ${ }^{1-3}$ and biotechnology 4,5 .
In this study, we focus on reversibly switchable fluorescent proteins (RSPFs) of the green fluorescent protein (GFP) family that can be reversibly photoswitched between a fluorescent on-state and a non-fluorescent off- or dark-state. Depending on whether the wavelength that excites fluorescence switches the RSFP from the on- to the off-state or vice versa, RSFPs are said to be negative or positive, respectively. ${ }^{6}$ In the absence of light, the metastable off-state (or on-state) spontaneously converts back to the thermodynamically stable onstate (or off state) on a time scale ranging from seconds to hours. A large number of RSFPs have been engineered from both hydrozoan and anthozoan fluorescent protein sequences. ${ }^{6-11}$ All of them share a common 11 -stranded $\beta$-barrel fold, enclosing an endogenous 4-( $\mathrm{p}$-hydroxybenzylidine)-5imidazolinone ( $p$-HBI) chromophore formed by a Xxx-TyrGly tri-peptide (where $\mathrm{Xxx}$ is a variable amino acid). During protein folding, in the presence of oxygen, this tripeptide autocatalytically transforms into a conjugated $\pi$-electron system consisting of two aromatic rings connected by a methine bridge. In solution, the isolated $p$-HBI chromophore can freely rotate around the $\mathrm{P}$ and I bonds of the methine bridge, which makes it non-fluorescent due to non-radiative de-excitation pathways. ${ }^{12-15}$ In GFPs, however, the chromophore is anchored to the protein scaffold in the center of the $\beta$-barrel by two short helices, as well as additional H-bonding, electrostatic and Van-der-Waals interactions with neighboring amino acids. This reduces the conformational flexibility of the chromophore, resulting in an up to 3-orders of magnitude increased fluorescence quantum yield (QY) compared to the same chromophore in solution. ${ }^{12,16}$ Even slight changes in the chromophore's local environment can significantly alter the photophysical properties of a RSFP, such as fluorescence quantum yield, photoswitching kinetics and photoswitching contrast. ${ }^{17}$ Understanding the relationship between changes in the chromophore's local environment, induced either by environmental physicochemical conditions or by mutations, and the observed photophysical properties is therefore of 
utmost importance for rational engineering of robust RSFP variants optimized for particular applications.

$\mathrm{X}$-ray crystal structures solved at cryogenic temperatures for a number of RSFPs ${ }^{6,11,18}$ have shown that the chromophore is generally found in a cis (or $Z$ ) configuration in the fluorescent on-state, while it adopts predominantly a trans (or $E$ ) configuration in the light-induced non-fluorescent off-state (an exception is the negative RSFP rsGamillus, where the chromophore adopts a trans configuration in the fluorescent on-state $\left.{ }^{19}\right)$. Except for rare cases, ${ }^{20}$ the resolution of these X-ray structures is not sufficient to observe the position of hydrogen atoms. Therefore, the protonation state of the chromophore and surrounding titrating residues has to be inferred from steric hindrance arguments, often leading to ambiguities. Additional information on the chromophore's protonation state can be obtained from optical methods, such as UV-visible or vibrational spectroscopy. These optical methods, however, are only poorly sensitive to cis-trans isomerization, making it challenging to disentangle cis-trans isomerization from protonation/deprotonation events. ${ }^{17,21,22}$ Protonation/deprotonation events of the chromophore and surrounding residues, as well as subsequent hydrogen bond formation and breakage play a major role in the relative stability of different chromophore configurational states, and the energy barriers between them. X-ray structures solved at cryogenic temperatures also lack information on the presence of multiple conformations that are in conformational exchange at various time scales.

High-field multidimensional solution Nuclear Magnetic Resonance (NMR) spectroscopy is a particularly powerful tool to investigate at atomic resolution the conformational dynamics of proteins under different environmental conditions. In particular, NMR chemical shifts are sensitive to protonation/deprotonation events and the formation of hydrogen bonds, both being influenced by $\mathrm{pH}$ and buffer composition. We have chosen rsFolder ${ }^{11}$ as a model protein for a negative RSFP for our NMR study. X-ray crystal structures of rsFolder in the dark-adapted on-, and light-induced off-states revealed a change in the chromophore configuration from cis (fluorescent on-state) to trans (non-fluorescent off-state). Recently, we have reported NMR assignments $\left({ }^{1} \mathrm{H},{ }^{13} \mathrm{C},{ }^{15} \mathrm{~N}\right)$ of rsFolder in both the on- and off-states at physiological $\mathrm{pH}^{23}$ In this study, we assumed that the chromophore in the onand off-states was in an anionic cis and a neutral trans configuration, respectively. Here, we show that NMR spectroscopy has the resolving power to spectrally distinguish 4 different chromophore species, allowing accurate quantification of state populations under various sample conditions $(\mathrm{pH}$, buffer composition), as well as providing information on the conformational dynamics of the chromophore and surrounding residues in each state, and the exchange kinetics between them. We demonstrate the occurrence of significant $\mathrm{pH}$-induced ground-state chromophore isomerization in this negative green RSFP, even in the absence of light illumination. We also observe a complex $\mathrm{pH}$-dependent stabilization of the trans-chromophore and propose a mechanistic model that accounts for it. We discuss implications of our findings on the $\mathrm{pH}$-dependence of the photoswitching contrast, a critical parameter in nanoscopy approaches. ${ }^{24}$

\section{RESULTS \& DISCUSSION}

NMR spectral signatures of chromophore configurations

The $p$-HBI chromophore can adopt two (main) protonation states with the hydroxyphenyl moiety either protonated at the phenolic oxygen (neutral species, $\mathrm{N}$ ) or deprotonated (anionic species, A). In addition, the chromophore can undergo cis-trans isomerization around the imidazolinone bond (I-bond), yielding a total of at least 4 potentially populated chromophore states, as shown in figure 1.
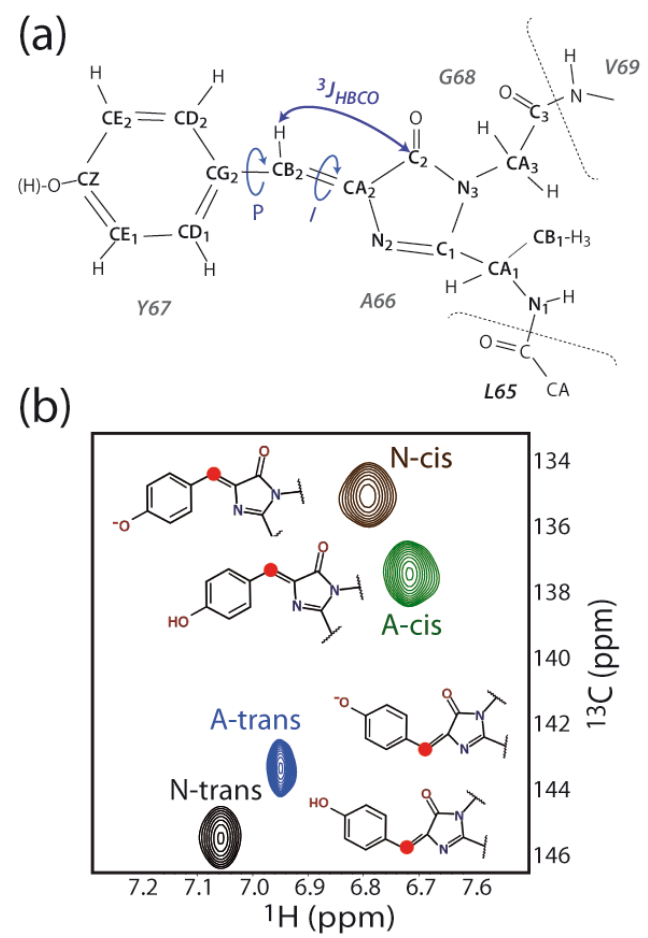

Figure 1. (a) Chemical structure and atom nomenclature of $p$ HBI chromophore formed by the tri-peptide A66-Y67-G68. The phenoxy $(\mathrm{P})$ and imidazolinone (I) bonds of the methine bridge are indicated. The 3-bond scalar coupling constant ${ }^{3} \mathrm{~J}_{\mathrm{HBCO}}$ is sensitive to I-bond rotations, allowing to differentiate between cis and trans isomers. (b) Characteristic NMR signature of the chromophore $\mathrm{CB}_{2}-\mathrm{H}$ pair (position highlighted in red on $p$-HBI structure) in the 4 configurational chromophore states: A-trans, A-cis, N-trans, and N-cis. Superposition of NMR signals recorded under different $\mathrm{pH}$ and illumination conditions: dark at $\mathrm{pH} 8$ (green), dark at $\mathrm{pH} 4.5$ (brown), 488-nm illumination at $\mathrm{pH} 8$ (black), 488-nm illumination at $\mathrm{pH} 11.5$ (blue).

Interestingly, we found that the $\mathrm{C}_{\beta}$ carbon $\left(\mathrm{CB}_{2}\right)$ of the chromophore's methine bridge exhibits a large ${ }^{13} \mathrm{C}$ chemical shift change $(\Delta \delta=7.6 \mathrm{ppm})$ upon photoswitching. The two correlation peaks observed at $\mathrm{pH} 7.5$ in the on- and off-states were assigned to the $\mathrm{A}$-cis and $\mathrm{N}$-trans configurations of the chromophore, respectively. At low $\mathrm{pH}$ (4.5), the NMR 
signature of the $\mathrm{CB}_{2}-\mathrm{H}$ pair in the off-state remains unchanged, while the on-state $\mathrm{CB}_{2}-\mathrm{H}$ peak is detected at a different position, tentatively assigned to the $\mathrm{N}$-cis configuration (figure S1a). At very high $\mathrm{pH}$ (11.5), two correlation peaks are detected for the $\mathrm{CB}_{2}-\mathrm{H}$ of the chromophore methine bridge under 488-nm light illumination (off-state), with the additional peak most likely arising from the A-trans species. It has been reported that ${ }^{3} \mathrm{~J}_{\mathrm{HBCO}}$ coupling constants (figure 1a) of synthetic $p$-HBI chromophore analogues are sensitive reporters of cis-trans isomerization of the I-bond ${ }^{25,26}$. NMR measurements of ${ }^{3} \mathrm{~J}_{\mathrm{HBCO}}$ coupling constants of rsFolder chromophore are in agreement with our assignment of these peaks, with values of $\sim 10 \mathrm{~Hz}$ for the trans configuration and $\sim 5 \mathrm{~Hz}$ for the cis configuration. Also the ${ }^{1} \mathrm{H}$ chemical shifts are in good qualitative agreement with those measured for isolated model GFP chromophores. ${ }^{25}$ The $\mathrm{CB}_{2}-\mathrm{H}$ correlation thus provides a convenient NMR signature (figure $\mathbf{1 b}$ ) for identifying the different chromophore species under a set of experimental conditions.

Similar NMR spectral signatures, characteristic of the 4 chromophore configurational states, are also observed for other protein backbone and sidechain nuclei that are in spatial proximity to the chromophore (figure $\mathbf{S 1 b}$ ). Of particular note is that chromophore cis-trans isomerization can cause significant chemical shift changes for nuclei, e.g. H-N pairs, far away from the chromophore (due to ring current shift effects). Therefore, measuring NMR peak intensities for nuclear sites that experience a strong chemical shift change upon chromophore isomerization, but that are only little affected by NMR line broadening, induced by exchange dynamics in the chromophore pocket allows accurate quantification of chromophore state populations.

Cis-chromophore protonation equilibrium and ring-flip dynamics

The relative populations of neutral and anionic chromophore species can be varied by adjusting the $\mathrm{H}+$ concentration in the solvent $(\mathrm{pH}) .2 \mathrm{D}^{1} \mathrm{H}^{-13} \mathrm{C}$ correlation spectra were recorded for a series of rsFolder samples in McIlvaine buffers (MI, mixture of disodium phosphate and citric acid), adjusted to $\mathrm{pH}$ values ranging from 4.2 to 8.0 (4.2 corresponding to the lowest $\mathrm{pH}$ value at which rsFolder does not show signs of protein unfolding over the NMR measurement time of several hours). These data revealed that the chromophore's $\mathrm{CB}_{2}-\mathrm{H}$ correlation peak is progressively shifting from the A-cis to the $\mathrm{N}$-cis position when lowering the $\mathrm{pH}$ (figure $\mathbf{2 b}$ ). The same behavior is observed for NMR signals of several side chain and amide backbone nuclei close to the chromophore in the $\beta$ barrel structure (figure 2a). The observed peak shifts are indicative of fast chromophore protonation/deprotonation exchange kinetics with an exchange rate constant $\mathrm{k}_{\mathrm{ex}}=\left(\mathrm{k}_{\mathrm{prot}}+\right.$ $\mathrm{k}_{\text {deprot }}$ ) >> $1000 \mathrm{~s}^{-1}$ over the entire $\mathrm{pH}$ range. This observation suggests that solvent hydrogens can easily migrate into the $\beta$ barrel and protonate the hydroxybenzylidine ring of the cischromophore on a sub-milliseconds time scale. The $\mathrm{pH}$-induced chemical shift variations measured for a total of 12 nuclei fit well to a simple bimolecular reaction as described by the Henderson-Hasselbalch equation with an apparent $\mathrm{pKa}$ value of $\mathrm{pK}_{\mathrm{cis}}=5.45 \pm 0.05$, and a Hill coefficient of 1 (figures 2c and S2). NMR spectra recorded for rsFolder dissolved in a phosphate-free HEPES buffer at $\mathrm{pH} 6$ reveal increased line broadening for nuclei that show $\mathrm{pH}$-induced peak shifts compared to spectra recorded in the phosphate-containing MI buffer (figure 2d). It is well known that phosphate ions can catalyze proton transfer reactions ${ }^{27-30}$ and indeed, when adding phosphate to the HEPES buffer, the spectral intensities observed in MI buffer are restored (figure S3). These observations can be explained by slower protonation/deprotonation exchange kinetics in the absence of phosphate in the sample solution, shifting the kinetic time scale to the intermediate exchange regime $\left(\mathrm{k}_{\mathrm{ex}} \approx 1000 \mathrm{~s}^{-1}\right)$, responsible for the observed NMR line broadening. In order to further quantify the exchange dynamics underlying the observed line broadening, we have performed ${ }^{15} \mathrm{~N}$ Carr-Purcell-Meiboom-Gill (CPMG) relaxation-dispersion (RD) NMR measurements. ${ }^{27,28}{ }^{15} \mathrm{~N}$ CPMG-RD data contain information on the lifetimes of the exchanging states, their relative populations, and the chemical shift differences between them. The ${ }^{15} \mathrm{~N}$ CPMG-RD data obtained for 6 amide sites of rsFolder at two different magnetic field strengths are plotted in Figure S4. For data fitting, we assumed a 2-state (A-cis and $\mathrm{N}$-cis) exchange model with the respective populations at $\mathrm{pH} 6.2$ equal to 0.85 (A-cis) and 0.15 (N-cis), as deduced from the Henderson-Hasselbalch equation with the $\mathrm{pK}_{\mathrm{cis}}=5.45$. A global fit of the CPMG-RD data to this exchange model leads to an excellent agreement between measured and back-calculated data for an exchange rate constant $\mathrm{k}_{\mathrm{ex}}=3200 \pm 200 \mathrm{~s}^{-1}$. This result indicates that the NMR line broadening observed for the 6 amide sites is caused by a single kinetic process, i.e. the exchange of the anionic and neutral cis chromophore states. In order to further validate this assumption, we compared the ${ }^{15} \mathrm{~N}$ chemical shift changes extracted from the $\mathrm{pH}$ titration series (figure S2) with those obtained from fitting the ${ }^{15} \mathrm{~N}$ CPMG-RD dispersion data (figure S4), resulting in the correlation plot shown in figure $2 \mathbf{e}$.

Protonation and deprotonation of the cis-chromophore in rsFolder is substantially accelerated by the presence of phosphate ions. Although molecular dynamics simulations indicate that small molecules such as oxygen may penetrate within the $\beta$-barrel of fluorescent proteins, ${ }^{29,30}$ it remains unclear whether phosphate can diffuse towards the rsFolder chromophore's phenyl moiety at a sufficiently fast rate. $\mathrm{pH}$-jump studies of the green fluorescent protein EGFP ${ }^{31,32}$ have shown that the rate-limiting step of cis-chromophore (de)protonation is the transfer of protons through the protein matrix via a network of proton acceptors and donors ${ }^{32-34}$. Thus, the observed increased (de)protonation exchange rate is more likely explained by a raise in proton shuttling efficiency at the accessible protein surface due to the catalytic action of phosphate ions. 
(a)

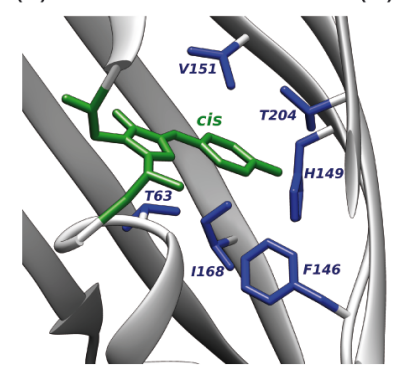

(c)

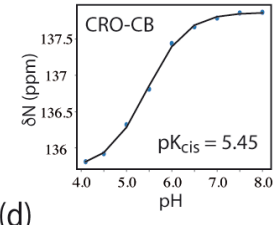

(d)
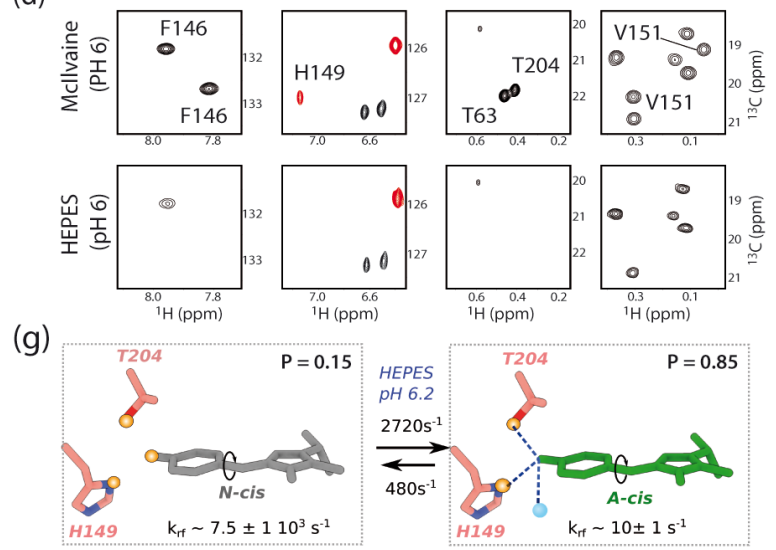

Figure 2. $\mathrm{pH}$ dependence of cis-chromophore protonation and dynamics. (a) Zoom on the cis-chromophore environment extracted from the X-ray structure of rsFolder on-state (PDB: 5DTZ $)^{11}$. Side chains with nuclei that show large $\mathrm{pH}$-dependent chemical shift changes are highlighted in blue. (b) $\mathrm{pH}$-titration effects observed in the NMR spectra for the $\mathrm{CB}_{2}-\mathrm{H}$ of the methine bridge and other nuclei close to the chromophore. 6 spectra recorded in the $\mathrm{pH}$ range from 7.5 to 4.2 (as indicated by an arrow) are superposed and color-coded to distinguish different nuclear sites. (c) Fit of the observed chemical shift variations to a bimolecular reaction as described by the Henderson-Hasselbalch equation with a pKa of 5.45. (d) Spectral differences in the aromatic and methyl regions of ${ }^{1} \mathrm{H}-{ }^{13} \mathrm{C}$ correlation spectra of rsFolder $\left(850 \mathrm{MHz}, 40^{\circ} \mathrm{C}\right)$ in the dark-adapted on-state at $\mathrm{pH} 6$ induced by a different buffer medium: MI buffer (top panel) or HEPES buffer (bottom panel). Red peaks are detected with negative signal intensity due to constant-time ${ }^{13} \mathrm{C}$ frequency editing. (e) Linear correlation of chemical shift differences extracted from the $\mathrm{pH}$ titration series and ${ }^{15} \mathrm{~N}$ CPMG-RD data. A correlation coefficient of 0.95 between the 2 data sets is obtained for linear regression with a slope of $\mathrm{m}=0.82$ (straight line), supporting our exchange model. Note that the deviation from $\mathrm{m}=1$ (dashed line)may be easily rationalized by a slight mis-calibration of the sample $\mathrm{pH}$ (about $0.1 \mathrm{pH}$ units). (f) Numerical fit of EXSY NMR data recorded for the $\mathrm{CE}$ sites of the hydroxybenzylidine ring at $\mathrm{pH} 7.5$ providing an estimate of the ring flip rate around the $\mathrm{P}$ bond. (g) Graphical sketch summarizing the major findings on the (de)protonation kinetics, ring-flip dynamics, and H-bond stabilization of the cis-chromophore in rsFolder. Yellow and blue balls represent hydrogen atoms and water molecules, respectively.

The cis chromophore can rotate around the phenoxy $(\mathrm{P})$ bond of the methine bridge, leading to aromatic ring flips. Ring flip rates for solvent-exposed tyrosine side chains on the order of $10^{3}-10^{5} \mathrm{~s}^{-1}$ have been reported at ambient temperature. ${ }^{35}$ For rsFolder, distinct NMR signals are detected for the $\mathrm{CD}$ and $\mathrm{CE}$ sites of the hydroxybenzylidine ring at $40^{\circ} \mathrm{C}$ and high $\mathrm{pH}(\geq 7)$, indicating slow ring flip dynamics in the A-cis state under these conditions. With decreasing $\mathrm{pH}$, these NMR signals strongly line broaden or even completely disappear from the spectra when the apparent ring-flip rate, resulting from the population-weighted average of the $\mathrm{A}$-cis and $\mathrm{N}$-cis ring flips, becomes comparable to the chemical shift difference of the 2 magnetically equivalent sites $\left(\omega_{\mathrm{CD} 1}-\omega_{\mathrm{CD} 2}\right.$, or $\left.\omega_{\mathrm{CE} 1}-\omega_{\mathrm{CE} 2}\right)$. At low $\mathrm{pH}(\leq 5.5)$, a single peak is detected for the CE position (figure S5a), while the CD site remains unobserved, due to the larger chemical shift difference between $\omega_{\mathrm{CD} 1}$ and $\omega_{\mathrm{CD} 2}$.

In the slow exchange regime, observed at high $\mathrm{pH}$, the ring flip kinetics can be further quantified by $2 \mathrm{D}$ exchange spectroscopy (EXSY) ${ }^{36}$ that monitors the intensity build-up of cross peaks correlating the ${ }^{13} \mathrm{C}$ frequency of one site with the ${ }^{1} \mathrm{H}$ frequency of the second site (figures $\mathbf{2 f}$ and $\mathbf{S 5 b}$ ). We have measured the ring flip rate $\mathrm{k}_{\mathrm{rf}}$ of the cis chromophore at 3 different $\mathrm{pH}$ values using such an EXSY experiment (figure S5c), resulting in exchange rate constants $\mathrm{k}_{\mathrm{ex}}=2 \mathrm{k}_{\mathrm{rf}}$ of $26 \pm 2$ $\mathrm{s}^{-1}$ ( $\left.\mathrm{pH} 10.7\right), 70 \pm 5 \mathrm{~s}^{-1}(\mathrm{pH} 7.5)$, and $230 \pm 50 \mathrm{~s}^{-1}(\mathrm{pH} 7.2)$. In addition, the observed coalescence (extreme line broadening) of the two CE-HE correlation peaks at about $\mathrm{pH} 6$, allows to estimate the exchange rate at this particular $\mathrm{pH}$ to be $\mathrm{k}_{\mathrm{ex}} \approx$ $1 /(2 \pi \Delta v)=3500 \mathrm{~s}^{-1}$. As expected, the ring flip rate increases with decreasing $\mathrm{pH}$, as a consequence of $\mathrm{N}$-cis becoming more populated. Individual ring-flip rates of the $\mathrm{A}$-cis and $\mathrm{N}$-cis states were obtained by fitting the measured data to a Henderson-Hasselbalch equation with a pKa of 5.45, describing the population average of the 2 states (figures S5d). Our data demonstrate that the P-bond in the A-cis state is very rigid with a ring-flip rate of only $10 \pm 1 \mathrm{~s}^{-1}$ at $40^{\circ} \mathrm{C}$, while the flexibility of the P-bond in the $\mathrm{N}$-cis state, with an extrapolated rate constant $\mathrm{k}_{\mathrm{rf}}=7.5 \pm 0.110^{3} \mathrm{~s}^{-1}$, is comparable to a free chromophore in solution. This finding provides an explanation for the non-fluorescence of the $\mathrm{N}$-cis state upon absorption at 405 $\mathrm{nm}$, which may apply to many GFPs when no excited state proton transfer occurs.

\section{The role of $\mathrm{H} 149$ in proton transfer}

H149 has been shown to be a critical residue in the photoswitching mechanism of rsEGFP2, notably involved in chromophore deprotonation upon trans-cis isomerization. ${ }^{37}$ Our crystallographic, ${ }^{11}$ and $\mathrm{NMR}^{23}$ data indicate that, in rsFolder, $\mathrm{H} 149\left(\mathrm{ND}_{1}\right)$ is forming a hydrogen bond with the phenolate ring of the anionic A-cis chromophore. With 
increasing population of the neutral $\mathrm{N}$-cis configuration, the $\mathrm{ND}_{1}$-H NMR signal observed at high $\mathrm{pH}$ is no longer detected at lower $\mathrm{pH}$ (figure S6a). This confirms that this $\mathrm{H}$-bond is constantly breaking and reforming as a consequence of proton exchange at the chromophore hydroxybenzylidine ring. Our NMR data also provide valid information about the tautomeric state of the histidine ring after protonation of the cischromophore. While the $\mathrm{CE}_{1}$ is a sensitive reporter of the charge state of the imidazole ring (neutral or cationic), the $\mathrm{CD}_{2}$ and $\mathrm{CG}$ chemical shifts report on its tautomeric state: $\mathrm{ND}_{1}-\mathrm{H}$ or $\mathrm{NE}_{2}-\mathrm{H}$ (figure $\mathbf{S 6} \mathbf{b}$ ). The $\mathrm{CE}_{1}, \mathrm{CG}$ and $\mathrm{CD}_{2}$ frequencies of $\mathrm{H} 149$ are only slightly changing between the A-cis (high $\mathrm{pH}$ ) and $\mathrm{N}$-cis (low $\mathrm{pH}$ ) conformations (figure S6c), indicating that the average charge and tautomeric state populations are only little altered by the proton transfer reaction. $\mathrm{H} 149$ remains predominantly in a $\mathrm{ND}_{1}-\mathrm{H}$ tautomeric configuration. Consequently, if $\mathrm{H} 149$ is the proton donor of the cis chromophore, it has to be part of a more extended protonation chain, allowing the imidazole ring to become quickly reprotonated at the $\mathrm{N}_{\delta 1}$ position, in agreement with previous proposals on EGFP. ${ }^{33,38}$

The graphical sketch in figure $\mathbf{2 g}$ summarizes our NMR findings about the protonation kinetics, conformational dynamics, and hydrogen bonding of the cis chromophore in rsFolder.

Trans-chromophore protonation equilibria and ring-flip dynamics

In the off-state of rsFolder, no significant changes of NMR chemical shifts are observed for the $\mathrm{CB}_{2}$ - $\mathrm{H}$ moiety of the chromophore and nuclei of surrounding residues in the $\mathrm{pH}$ range 4.5-11.5 (figures 3 and S1). However, an additional NMR signal, assigned to an A-trans chromophore configuration is detected at $\mathrm{pH}$ 11.5. This is in agreement with the $\mathrm{pKa}$ of the trans-chromophore (de)protonation equilibrium being shifted to high $\mathrm{pH}(>10)$, as reported for other RSFPs. ${ }^{39}$ Assuming a simple bimolecular process, we can estimate the $\mathrm{pKa}$ from the $\mathrm{N}$-trans and A-trans populations measured at $\mathrm{pH}$ 11.5 to be $\mathrm{pK}_{\text {trans }}=12.0 \pm 0.1$ in rsFolder. This $\mathrm{pKa}$ is about 3 $\mathrm{pH}$ units higher than what is observed for a hydroxyphenyl ring in aqueous solution. ${ }^{40}$ Contrary to the situation observed for the cis-chromophore in rsFolder, where the NMR signals of nuclei in the proximity of the chromophore shift as a function of $\mathrm{pH}$, two distinct peaks are detected for rsFolder in the trans-chromophore isomeric state, indicative of proton exchange kinetics $k_{e x}<<1000 \mathrm{~s}^{-1}$. Proton transfer in rsFolder trans-chromophore is thus a much slower process than in rsFolder cis-chromophore, a consequence of the absence of efficient proton transfer pathways that allow to quickly evacuate a proton from the hydroxyphenyl ring to the bulk water.

No NMR signals could be detected for the symmetrical CD and $\mathrm{CE}$ sites of the hydroxybenzylidine ring of the trans-chromophore independent of $\mathrm{pH}$ and buffer composition. This indicates that the P-bond in the $\mathrm{N}$-trans state is rotating at an intermediate flip rate that we can estimate (from the cis-chromophore chemical shifts) to be in the range $\mathrm{k}_{\mathrm{rf}} \approx 300-1000$ $\mathrm{s}^{-1}$ or undergoes different types of millisecond time scale motion inside the $\beta$-barrel.
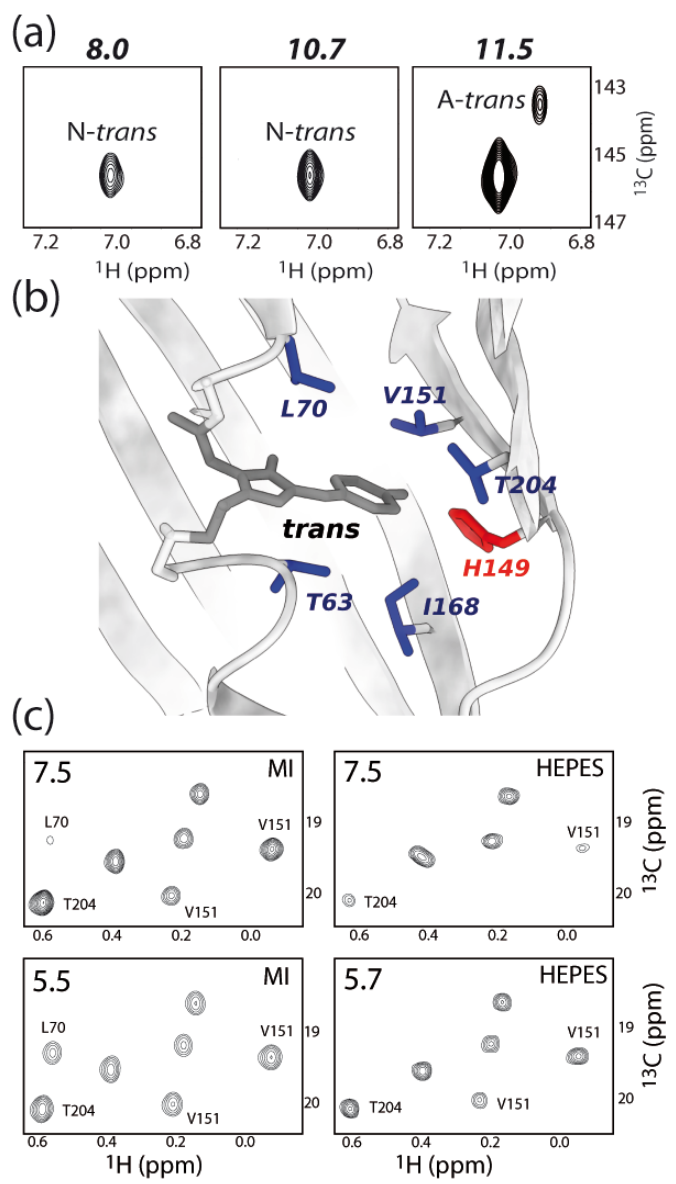

Figure 3. (a) NMR signature of the chromophore's $\mathrm{CB}_{2}-\mathrm{H}$ moiety in the trans configuration, recorded under 488-nm illumination at $40^{\circ} \mathrm{C}$ for different $\mathrm{pH}$ values. The observed peaks are annotated. (b) Zoom on the trans-chromophore environment extracted from the X-ray structure of rsFolder off-state (PDB: 5DU0) ${ }^{11}$ Side chains with nuclei that show $\mathrm{pH}$ - and buffer-dependent line broadening in the methyl spectra shown in (c) are highlighted in blue, while $\mathrm{H} 149$ at the origin of this NMR line broadening is color-coded in red. (c) Methyl region of ${ }^{1} \mathrm{H}-{ }^{13} \mathrm{C}$ correlation spectra, recorded under 488 -nm illumination at $40^{\circ} \mathrm{C}$ for different $\mathrm{pH}$ values (as indicated) and buffer conditions (MI or HEPES). The slight difference in the acidic $\mathrm{pH}$ values for HEPES and MI is insignificant for our conclusions.

In our recent NMR study, ${ }^{23}$ we could show that the chromophore pocket and parts of the $\beta$-barrel in the $\mathrm{N}$-trans state of rsFolder in HEPES buffer at $\mathrm{pH} 7.5$ are dynamic with conformational sub-states interconverting on the millisecond time scale, as inferred from extensive NMR line broadening observed for backbone and side chain resonances close to the chromophore (figure $\mathbf{3 b}$ ). Interestingly, these line broadening effects are $\mathrm{pH}$ and buffer dependent. In particular, they are considerably reduced when replacing the organic HEPES buffer with a phosphate-containing MI buffer, or by lowering the $\mathrm{pH}$ (figure 3c). These observations indicate that the conformational dynamics underlying the NMR line broadening 
are related to a second (de)protonation event in the chromophore pocket, different from the protonation of the chromophore's phenyl ring. As will be discussed in more detail below, the most likely candidate titrating in the $\mathrm{pH}$ range $5.5-7.5$ is the imidazoline ring of $\mathrm{H} 149$.

Thermodynamics and kinetics of cis-trans chromophore isomerization in the dark

Quantitative information about the free-energy difference between the cis and trans chromophore configurations in rsFolder is obtained from NMR measurements of state populations. The trans-chromophore population calculated from $\mathrm{CB}_{2}-\mathrm{H}$ peak intensities, measured in ${ }^{1} \mathrm{H}^{13} \mathrm{C}$ correlation spectra (figure S7a) as a function of $\mathrm{pH}$, is plotted in figure $\mathbf{4 a}$. The $p$-HBI chromophore in rsFolder undergoes $\mathrm{pH}$-induced cis-trans isomerization, with the population of the trans configuration increasing at lower $\mathrm{pH}$ values, and reaching a maximum value of $30 \%$ at $\mathrm{pH}$ 5.0. At even lower $\mathrm{pH}$, the transchromophore configuration decreases again, and is no longer detected at $\mathrm{pH}$ 4.2. The same $\mathrm{pH}$-dependent behavior is observed for amide backbone ${ }^{1} \mathrm{H}_{-}{ }^{15} \mathrm{~N}$ correlations that show significant chemical shift changes upon cis-trans chromophore isomerization (figure S7b). $\mathrm{pH}$-induced chromophore cistrans isomerization in the electronic ground state has been previously observed in non-reversibly photoswitchable fluorescent proteins such as $\mathrm{mKate}{ }^{41}$ and $\mathrm{mKeima}^{42}$. However, for these proteins, a complete switch of isomeric state is observed at low $\mathrm{pH}$ relative to high $\mathrm{pH}$, while a mixed population between cis and trans configurations of the chromophore is observed at intermediate $\mathrm{pH}$ values. The partial occupancy of the trans-isomeric state at around $\mathrm{pH} 5.0$ is thus (so far) unique to rsFolder. Its mechanistic interpretation is most likely related to the presence of a titrable residue in the immediate vicinity of the chromophore changing its protonation state with a $\mathrm{pKa}$ close to $\mathrm{pH} 5$.

The $\mathrm{pH}$-dependent build-up of $\mathrm{N}$-trans species in the dark has also implications for the apparent pKa obtained from fluorescence or absorbance measurements. While NMR chemical shifts report on the $\mathrm{pKa}$ of chromophore protonation/deprotonation in the pure isomeric cis-state, optical measurements typically probe the amount of the fluorescent A-cis species as a function of $\mathrm{pH}$, which results from the combined effect of protonation, as well as cis-trans isomerization (figure S8).

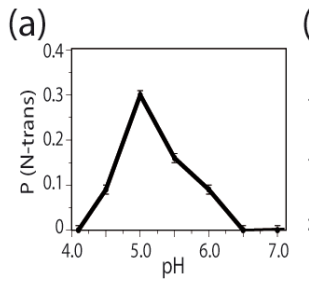

(b)

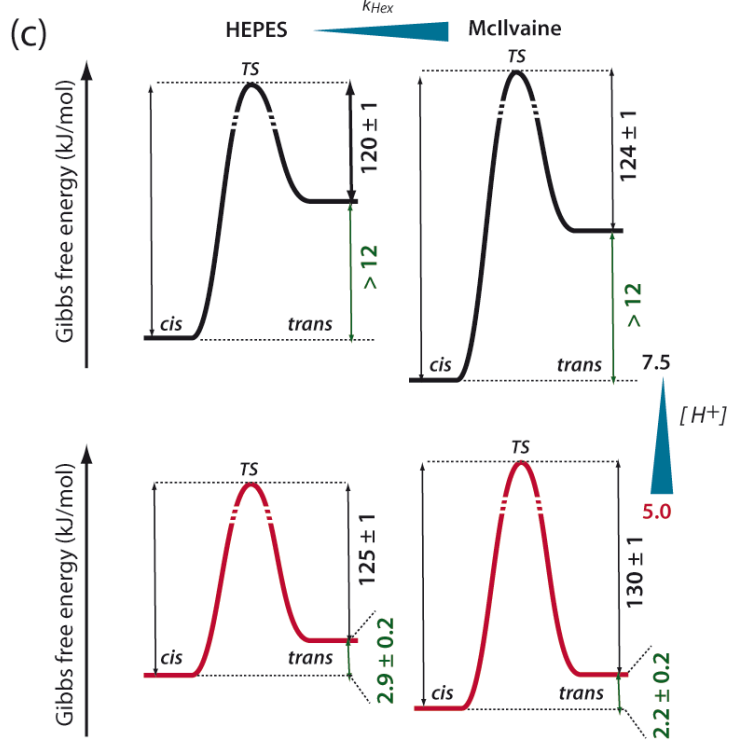

Figure 4. (a) N-trans population measured as a function of $\mathrm{pH}$ from the CB-HB peak intensities in the absence of light. (b) Normalized thermal relaxation kinetics observed for rsFolder in MI buffer at different $\mathrm{pH}$ values. For better visibility, data for $\mathrm{pH}<$ 5.0 are plotted in blue. (c) Energy landscape of cis-trans isomerization in rsFolder derived from the NMR data shown in (a) and (b) for different $\mathrm{pH}$ (black: 7.5 and red: 5.0) and buffer composition (left: HEPES and right: MI).

Additional information on the free energy landscape of rsFolder cis-trans isomerization is obtained from thermal relaxation measurements. The trans-chromophore can be populated to a high level by 488 -nm sample illumination. In the dark, this light-induced trans-chromophore population spontaneously reconverts to the cis-chromophore configuration until reaching a thermodynamic equilibrium. Thermal relaxation kinetics can be accurately quantified by measuring the intensity decay or build-up of NMR signals characteristic for one of the 2 states. Figure $4 \mathbf{b}$ shows our NMR results of transto-cis interconversion measurements at $40^{\circ} \mathrm{C}$ for a range of rsFolder samples in MI buffers at different $\mathrm{pH}$ values. The observed $\mathrm{pH}$ dependence of thermal relaxation times is similar to what we reported in figure $\mathbf{4 a}$ for the trans-chromophore population: the thermal relaxation time increases from 14 hours at $\mathrm{pH} 7.5$ to a maximum of 125 hours at $\mathrm{pH} 5.0$, before decreasing again to 16 hours at $\mathrm{pH} 4.2$. In order to derive energy barriers between the trans-chromophore state and the transition state(s) along the pathway to the cis-chromophore state, we have measured the temperature dependence of thermal relaxation at $\mathrm{pH} 7.5$ in HEPES buffer. Using an Arrhenius relation we determined the activation energy for trans-to-cis 
conversion in the dark to be $120 \pm 5 \mathrm{~kJ} / \mathrm{mol}$ under these conditions (figure S9). We have also remeasured some NMR data ( $\mathrm{pH} 7.5$ and 5.0) in HEPES buffer (figure S10) in order to evaluate the influence of buffer composition, and in particular the presence of phosphate ions, on the energetic landscape of cis-trans isomerization. The resulting free energy landscapes for MI and HEPES buffer at $\mathrm{pH} 7.5$ and 5.0, assuming a 2-state exchange process with a single activation energy barrier, are shown in figure 4c. Our NMR-derived energy landscapes do not provide absolute values for the freeenergies of the cis and trans chromophore states, but only information on activation energies (energy difference between the ground and transition state). Therefore, the observation of a reduced activation energy may be explained by either higher energy of the ground state, or lower energy of the transition state, or both.

Concerning the cis-chromophore, we observe a reduction in activation energy at low $\mathrm{pH}$, which may be ascribed to an increasing amount of $\mathrm{N}$-cis population $(<1 \%$ at $\mathrm{pH} 7.5$ versus $74 \%$ at $\mathrm{pH} 5$ ). The observed energy difference is thus mainly due to enthalpic stabilization of the A-cis chromophore by $\mathrm{H}$ bonding to the $\beta$-barrel that is lost after protonation of the chromophore's hydroxyphenyl moiety. In contrast, in the case of the trans-chromophore, our data indicate a higher activation energy at $\mathrm{pH}$ 5.0, which we relate to the data in figure 4a that suggest a stabilization of the rsFolder trans-chromophore state at this $\mathrm{pH}$.

Interestingly, in both directions, we observe that the activation energy for chromophore isomerization in the electronic ground state is decreased in a HEPES buffer, as compared to a MI buffer, that is, if the proton exchange kinetics are slowed down. We currently do not have a clear explanation for this observation, which may however be tentatively ascribed to a destabilization of the transition state(s) between the cis and trans conformational states.

Potential role of $\mathrm{H} 149$ in trans-chromophore stabilization at $\mathrm{pH} 5$

We do not have direct evidence of what is causing the apparent trans-chromophore stabilization at $\mathrm{pH} 5.0$, but we speculate that hydrogen bonding of the hydroxyl group of the chromophore with the imidazoline ring of $\mathrm{H} 149$ is the main driving force. Such $\mathrm{H}$-bond formation has been observed at lowtemperature in the X-ray structure of rsFolder in its off-state. ${ }^{11}$ In order to be a proton acceptor, the H149 side chain has to be in a neutral state, i.e. protonated only on one of the ring nitrogens. As discussed above, NMR provides a valuable tool to infer the tautomeric and charge state of histidine side chains. The $\mathrm{CE}_{1}(\mathrm{H})$ frequencies of $\mathrm{H} 149$ are only slightly changed after chromophore isomerization, indicating that the imidazoline ring remains predominantly neutral at $\mathrm{pH}>5$. Furthermore, we could not detect any NMR signal for the $\mathrm{CD}_{2}$ and $\mathrm{CG}$ sites, which are sensitive to the tautomeric state, over the entire sampled $\mathrm{pH}$ range. This may be explained by extensive NMR line broadening due to the interconversion of $\mathrm{ND}_{1}-\mathrm{H}$ and $\mathrm{NE}_{2}-\mathrm{H}$ tautomeric states at the millisecond time scale. At $\mathrm{pH} 5.0$ and/or in the presence of phosphate ions, we observe NMR line narrowing for nuclei close to H149 (figure 3c). This can be ascribed to accelerated exchange kinetics, as confirmed by the temperature dependence of the observed line broadening effects (figure S11a), shifting the exchange kinetics out of the intermediate NMR exchange regime for nuclear sites with relatively small chemical shift differences between the 2 states. The expected large chemical shift differences for the $\mathrm{CD}_{2}$ (4 ppm) and CG (9 ppm) of the $\mathrm{H} 149$ side chain (figure S6b) explain why these resonances remain unobserved in our NMR spectra. Furthermore, we hypothesize that the equilibrium is shifted towards the $\mathrm{N}^{\varepsilon 2} \mathrm{H}$ tautomeric state at $\mathrm{pH}$ 5.0, favoring H-bond formation with the chromophore, as illustrated in figure $\mathbf{5}$.
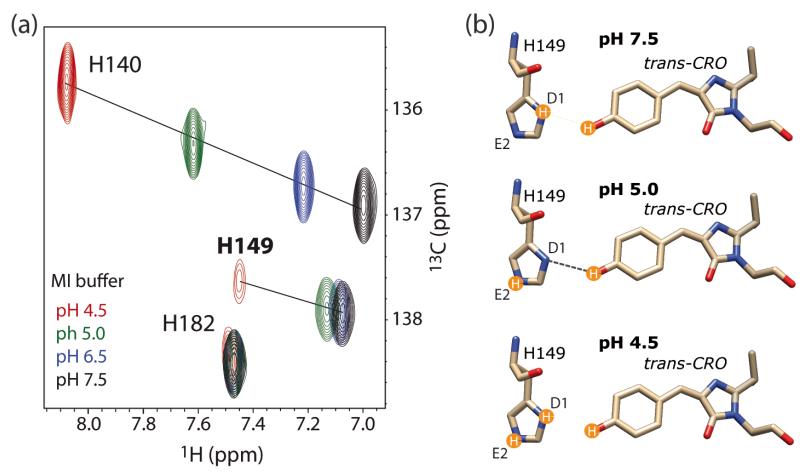

Figure 5. (a) Spectral overlay of color-coded ${ }^{1} \mathrm{H}^{-13} \mathrm{C}$ correlation spectra, highlighting the different titration behavior of 3 histidine $\mathrm{CE}_{1}-\mathrm{H}$ side chain resonances as a function of $\mathrm{pH}$. While $\mathrm{H} 182$ remains in a neutral tautomeric state over the whole $\mathrm{pH}$ range, $\mathrm{H} 140$ is titrating like a free histidine in solution with a $\mathrm{pKa}$ of $\sim 6.5$, and $\mathrm{H} 149$ only starts shifting significantly below $\mathrm{pH} 5$. (b) During $\mathrm{pH}$ titration, the relative populations of $\mathrm{H} 149$ tautomeric states shift from predominantly $\mathrm{ND}_{1}$-protonated (high $\mathrm{pH}$ ), $\mathrm{NE}_{2}$-protonated ( $\mathrm{pH} \mathrm{5)}$, to bi-protonated (low $\mathrm{pH}$ ). Only the $\mathrm{NE}_{2}$-protonated tautomer can form a $\mathrm{H}$-bond with the protonated chromophore.

This population shift is supported by small chemical shift changes observed in the off-state of rsFolder for some of the side chain nuclei in the vicinity of $\mathrm{H} 149$ in the $\mathrm{pH}$ range between 5.0 and 7.5 (figure $\mathbf{S 1 1 b}$ ). The $\sim 5-6 \mathrm{~kJ} / \mathrm{mol}$ difference observed between the activation energies of the transchromophore state at $\mathrm{pH} 7.5$ and 5.0 is within the reported range of hydrogen-bond formation in proteins ${ }^{43,44}$, and therefore further supports our model of stabilization of a single $\mathrm{H}$ bond between the hydroxyl group of the chromophore and the imidazoline ring of $\mathrm{H} 149$.

At $\mathrm{pH}<5$, a cationic form of $\mathrm{H} 149$ becomes increasingly populated as deduced from characteristic $\mathrm{CE}_{1}-\mathrm{H}$ frequency shifts observed at low $\mathrm{pH}$ (figure 5a). The doubly-protonated histidine side chain is no longer able to form a $\mathrm{H}$-bond with the $\mathrm{N}$-trans chromophore, thus explaining the energetic destabilization of the trans-CRO under such acidic conditions. 
Chromophore state populations under light illumination and switching contrast

In order to investigate the consequences of the observed $\mathrm{pH}$-induced ground-state free energy changes for photoswitching nanoscopy techniques such as Reversible Saturable Optical Fluorescence Transition (RESOLFT) microscopy, we also measured chromophore state populations under light illumination conditions.
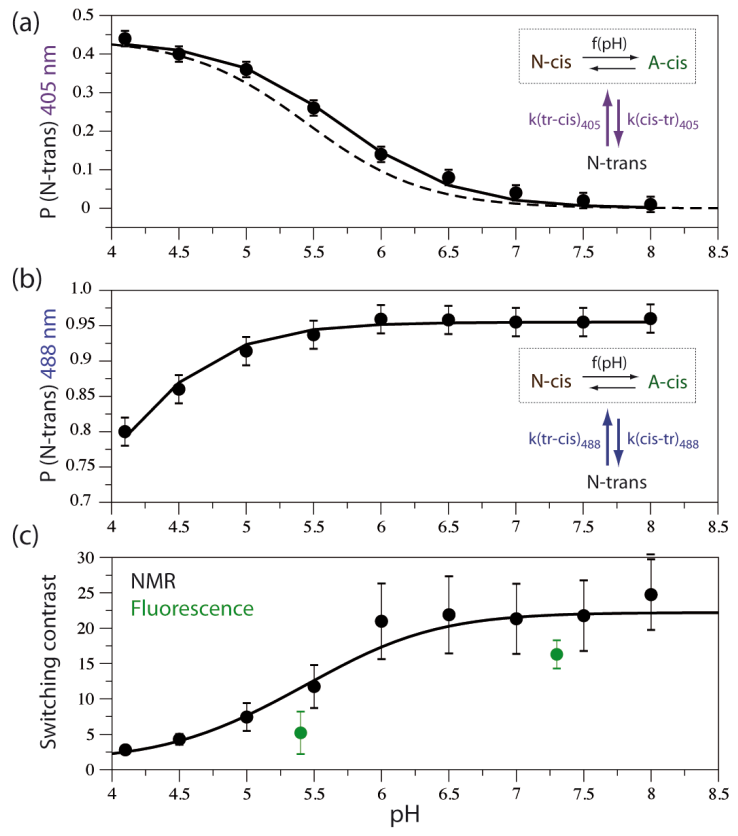

Figure 6. NMR measurements of the $\mathrm{pH}$ dependence of $\mathrm{N}$-trans chromophore populations in rsFolder under continuous (a) 405$\mathrm{nm}$ and (b) 488-nm light illumination. The straight lines are fits of the experimental data to a Henderson-Hasselbalch relation, while the dashed line in (a) is the calculated behavior for a $\mathrm{pKa}$ of 5.45. A kinetic model is shown in the insert. (c) NMR-derived switching contrast (black points), calculated as $\mathrm{P}(\mathrm{A}$ cis $)_{405} /\left(\mathrm{P}(\mathrm{A}-c i s)_{488}\right.$. In addition, the switching contrast measured by fluorescence microscopy on protein samples in highly concentrated MI buffers at $2 \mathrm{pH}$ values, and fixed in polyacrylamide gels, is plotted as green dots. The lower contrast observed by fluorescence microscopy as compared to NMR may be due to differences in sample conditions.

Figure 6 shows NMR-derived N-trans populations under continuous (a) 405-nm and (b) $488 \mathrm{~nm}$ illumination as a function of $\mathrm{pH}$. To analyze these data, we assume a simple kinetic model as depicted in the inserts of figures $\mathbf{6 a}$ and $\mathbf{6 b}$. The steady-state population reached at each $\mathrm{pH}$ is governed by the relative photoswitching rates at a particular wavelength between the $\mathrm{A} / \mathrm{N}$-cis and the $\mathrm{N}$-trans isomeric states, and by the $\mathrm{pH}$-dependent equilibrium of $\mathrm{N}$-cis and $\mathrm{A}$-cis populations. The latter assumption is supported by the fact that NMR onstate peak positions are not affected by illumination at either wavelength. The kinetic rate constants are given by the population-weighted (in the case of cis-chromophore) product of the extinction coefficient ( $\varepsilon_{\text {cis }}$ or $\varepsilon_{\text {trans }}$ ) of the cis or trans states at the actinic wavelength ( 405 or $488 \mathrm{~nm}$ ) and the respective switching quantum yield ( $\mathrm{QY}(\mathrm{tr}$-cis) or $\mathrm{QY}$ (cis-tr)). In the case of $\mathrm{pH}$-independent extinction coefficients and switching QY of the different chromophore species, the $\mathrm{N}$-trans population is expected to follow a Henderson-Hasselbalch relation with the $\mathrm{pKa}$ of the cis chromophore (5.45), as derived from our ground-state NMR data.

Under $405 \mathrm{~nm}$ illumination (figure 6a) and high $\mathrm{pH}$, the measured $\mathrm{N}$-trans population is close to zero, indicating that the A-cis chromophore (populated at close to 100\%) is not able to switch, and that the switching rate $\mathrm{k}$ (cis-tr) ${ }_{405}$ is solely determined by the properties (extinction coefficient and switching quantum yield) of $\mathrm{N}$-cis. At $\mathrm{pH}<4.0$, a N-trans population of about $0.45 \pm 0.05$ is observed which translates to comparable switching rates in both directions $\left(\mathrm{k}(\text { cis-tr })_{405} \approx\right.$ $\left.\mathrm{k}(\mathrm{tr} \text {-cis })_{405}\right)$. In other words, at acidic $\mathrm{pH}$ the extinction coefficients and switching QY of the N-cis and N-trans chromophore are similar, in agreement with our findings of highly dynamic chromophore moieties within the $\beta$-barrel structure of rsFolder. Fitting these data to a Henderson-Hasselbalch model yields an apparent pKa of 5.7 (solid line), $0.25 \mathrm{pH}$ units above the value of 5.45 (dashed line), expected for $\mathrm{pH}$-independent switching rates. Thus, the small, but significant deviation of the measured $\mathrm{N}$-trans populations from the simple kinetic model is most likely explained by a $\mathrm{pH}$-dependent $\mathrm{k}(\mathrm{tr}$ cis $)_{405}$ switching rate, caused by the transient stabilization of the N-trans chromophore by an $\mathrm{H}$-bond to $\mathrm{H} 149$ at intermediate $\mathrm{pH}$ values. This results in slightly increased $\mathrm{N}$-trans populations similar to the observed behavior in the ground state.

The $\mathrm{pH}$-dependence of the $\mathrm{N}$-trans population under 488 $\mathrm{nm}$ illumination (figure $\mathbf{6 b}$ ) can be fitted to the same kinetic model (straight line). The fitted "plateau" population of the $\mathrm{N}$-trans state at high $(>6)$ and very low $\mathrm{pH}(<2)$ are $0.955 \pm 0.005$ and $0.55 \pm 0.10$, respectively. Again, these data provide some insight into the relative switching rates at this wavelength. At acidic $\mathrm{pH}$, we find again similar switching rates, $\mathrm{k}$ (cis-tr $)_{488} \approx \mathrm{k}$ (tr-cis) ${ }_{488}$ for $\mathrm{N}$-cis and $\mathrm{N}$-trans chromophore species. The significantly increased $\mathrm{N}$-trans population at high $\mathrm{pH}$ originates from a switching efficiency $\mathrm{k}$ (cis-tr) ${ }_{488}$ that is about 22-times higher for a pure A-cis as compared to a pure $\mathrm{N}$-cis chromophore state. The apparent $\mathrm{pKa}$ of this $\mathrm{pH}$ dependence is 4.0, $1.5 \mathrm{pH}$ units below the ground-state $\mathrm{pKa}$ of the cis-chromophore. We tentatively assign this large $\mathrm{pKa}$ shift to an increased switching efficiency $\mathrm{k}$ (cis-tr) ${ }_{488}$ of the cis chromophore species at lower $\mathrm{pH}$ that partly compensates for the reduced A-cis population. The faster off-switching may be rationalized by a reduced transition state energy in the excited state due to the presence of an increasing amount of $\mathrm{H}^{+}$ions.

An important parameter for microscopy applications relying on reversible photoswitching of fluorescent markers is the switching contrast $\mathrm{C}$, defined as the ratio of fluorescence measured upon off-to-on switching with 405-nm light, and on-to-off switching with 488-nm light. Assuming that only the A-cis species is significantly fluorescent, a reduced switching contrast results from the combined effects of residual on-to- 
off switching by 405 -nm light and off-to-on switching by 488nm light: $\mathrm{C}=\mathrm{P}(\mathrm{A}-c i s)_{405} / \mathrm{P}(\mathrm{A}-c i s)_{488}$. Figure 6c shows a plot of the $\mathrm{pH}$-dependence of switching contrast as derived from the measured NMR chromophore state populations. Lowering the $\mathrm{pH}$ from 8 to 4 results in a reduction of switching contrast by one order of magnitude, as a combined effect of the higher amount of trans-chromophore species present after 405-nm illumination (accounts for a factor of 2), and the lower cis-to-trans switching efficiency under 488-nm illumination (accounts for a factor of 5). Our NMR-derived results are qualitatively confirmed by ensemble fluorescence measurements (figure S12) at $\mathrm{pH}$ values of 5.4 and 7.3.

\section{CONCLUSION}

We have demonstrated that NMR spectroscopy is a powerful tool to differentiate chromophore states in photo-transformable fluorescent proteins, that may become (simultaneously) populated in solution under a set of experimental conditions $(\mathrm{pH}$, temperature, buffer composition, ... ) either in the dark or under light illumination. The atomic resolution provided by NMR allows to accurately quantify state populations and their interconversion kinetics, adding important additional information to the static structures obtained from Xray crystallography. In addition, disentangling the various chromophore states offers a mean of investigating chromophore dynamics, H-bonding to the barrel, and on-off switching energy barriers that strongly influence the optical properties of these proteins, and their usefulness and limitations for particular microscopy applications. For the negative RSFP rsFolder, we could show that the $\mathrm{N}$-cis state behaves like a free chromophore in solution that undergoes non-radiative relaxation after light excitation making it a non-fluorescent species. In contrary, the A-cis chromophore is stabilized by $\mathrm{H}$-bonding to surrounding residues (and a water molecule), which heavily decreases its conformational dynamics, resulting in a 3-orders of magnitude reduction of the chromophore ring flip rate $\left(10 \mathrm{~s}^{-1}\right.$ at $\left.40^{\circ} \mathrm{C}\right)$. Although $\mathrm{H}$-bonding interactions with organic chromophores have been reported to induce fluorescence quenching by electron transfer mechanisms, ${ }^{45}$ in rsFolder, the NMR-observed conformational stabilization of the A-cis chromophore when $\mathrm{H}$-bonded to the $\beta$-barrel suggests that $\mathrm{H}$-bonding rather promotes a high fluorescence brightness in fluorescent proteins. Finally, the N-trans chromophore shows a $\mathrm{pH}$-dependent stabilization that we have attributed to transient $\mathrm{H}$-bond formation with the imidazoline ring of $\mathrm{H} 149$ that is most stable around $\mathrm{pH}$ 5. This stabilization significantly modulates cis-trans isomerization in the dark, and also contributes to a reduced switching contrast in fluorescence microscopy. Overall, our data show that the relative populations of fluorescent and non-fluorescent chromophore states vary in a complex $\mathrm{pH}$-dependent manner, with protonation and deprotonation events of the chromophore and nearby residues playing an important role in $\mathrm{H}$-bond dynamics altering the chromophore's conformational stability and its ability to photoswitch in the dark or under light illumination. We believe that using solution NMR spectroscopy to probe changes in chromophore state populations and dynamics provides a powerful new tool to investigate the effects of environmental conditions or protein mutations and to correlate them with altered photophysical properties, as a prerequisite for rational design of phototransformable fluorescent protein variants with improved properties.

\section{ASSOCIATED CONTENT}

\section{Supporting Information.}

The Supporting Information is available free of charge on the ACS Publications website.

Materials and Methods (sample preparation and experimental procedures); supplementary figures, presenting additional NMR and Absorbance/Fluorescence data (PDF).

\section{AUTHOR INFORMATION}

\section{Corresponding Author}

Bernhard Brutscher - Institut de Biologie Structurale, Université Grenoble Alpes, CEA, CNRS, Grenoble 38044, France ; Email : bernhard.brutscher@ibs.fr

\section{ACKNOWLEDGMENT}

Financial support from the CNRS (Défis Instrumentation 2018 grant), iNEXT-Discovery, project number 871037, funded by the Horizon 2020 program of the European Commission, and the Agence Nationale de la Recherche (grants no. ANR-17-CE110047-01 and ANR-20-CE11-0013-01 to D.B.) is acknowledged. This work used the NMR and isotope labeling platforms of the Grenoble Instruct-ERIC center (ISBG; UMS 3518 CNRS-CEA-UJF$E M B L)$ within the Grenoble Partnership for Structural Biology (PSB). Platform access was supported by FRISBI (ANR-10-INBS05-02) and GRAL, a project of the University Grenoble Alpes graduate school (Ecoles Universitaires de Recherche) CBH-EUR-GS (ANR-17-EURE-0003). IBS acknowledges integration into the Interdisciplinary Research Institute of Grenoble (IRIG, CEA). We thank Dr Paul Schanda for stimulating discussions, and for contributing a script for the analysis of EXSY data .

\section{REFERENCES}

(1) Nienhaus, K.; Nienhaus, G. U. Fluorescent Proteins for Live-Cell Imaging with Super-Resolution. Chem. Soc. Rev. 2014, 43, 1088-1 106. Quérard, J.; Zhang, R.; Kelemen, Z.; Plamont, M.; Xie, X.; Chouket, R.; Roemgens, I.; Korepina, Y.; Albright, S.; Ipendey, E.; Volovitch, M.; Sladitschek, H. L.; Neveu, P.; Gissot, L.; Gautier, A.; Faure, J.; Croquette, V.; Saux, T. Le; Jullien, L. Resonant Out-of-Phase Fluorescence Microscopy and Remote Imaging Overcome Spectral Limitations. Nat. Commun. 2017, 8 (969), 969.

(3) Vetschera, P.; Mishra, K.; Fuenzalida-werner, J. P.; Chmyrov, A.; Ntziachristos, V.; Stiel, A. C. Characterization of Reversibly Switchable Fluorescent Proteins in Optoacoustic Imaging. Anal. Chem. 2018, 90, 10527-10535.

Chirgwandi, Z. G.; Panas, I.; Johansson, L. G.; Norden, B.; Willander, M.; Winkler, D.; Agren H. Properties of a Biophotovoltaic Nanodevice. J. Phys. Chem. C 2008, 112, 18717-18721.

(5) Adam, V.; Mizuno, H.; Grichine, A.; Hotta, J.; Yamagata, Y.; Moeyaert, B.; Nienhaus, G. U.; Miyawaki, A.; Bourgeois, D.; Hofkens, 
. Data Storage Based on Photochromic and Photoconvertible Fluorescent Proteins. J. Biotechnol. 2010, 149 (4), 289-298.

Bourgeois, D.; Adam, V.; Fourier, J. Critical Review Reversible Photoswitching in Fluorescent Proteins: A Mechanistic View. IUBMB Life 2012, 64 (June), 482-491.

(7) Ando, R.; Flors, C.; Mizuno, H.; Hofkens, J.; Miyawaki, A. Highlighted Generation of Fluorescence Signals Using Simultaneous Two-Color Irradiation on Dronpa Mutants. Biophys. J. 2007, 92 (12), L97-L99. Ando, R.; Mizuno, H.; Miyawaki, A. Regulated Fast Nucleocytoplasmic Shuttling Observed by Reversible Protein Highlighting. Science (80-. ). 2004, 306 (5700), 1370-1373.

. Testa, I.; Grotjohann, T.; Leutenegger, M.; Plessmann, U.; Urlaub, H.; Eggeling, C.; Wahl, M. C.; Hell, S. W.; Jakobs, S. A Reversibly Photoswitchable GFP-like Protein with Fluorescence Excitation Decoupled from Switching. Nat. Biotechnol. 2011 , 29 (10), 942-947.

(10) Grotjohann, T.; Testa, I.; Reuss, M.; Brakemann, T.; Eggeling, C.; Hell, S. W.; Jakobs, S. RsEGFP2 Enables Fast RESOLFT Nanoscopy of Living Cells. Elife 2012, 1, e00248.

(11) El Khatib, M.; Martins, A.; Bourgeois, D.; Colletier, J.; Adam, V.; Khatib, M. El; Martins, A.; Bourgeois, D.; Colletier, J.; Adam, V. Rational Design of Ultrastable and Reversibly Photoswitchable Fluorescent Proteins for Super-Resolution Imaging of the Bacterial Periplasm. Sci. Rep. 2016, 6 (October 2015), 18459.

(12) Wu, L.; Burgess, K. Syntheses of Highly Fluorescent GFPChromophore Analogues. J. Am. Chem. Soc. 2008, 130, 4089-4096.

(13) Megley, C. M.; Dickson, L. A.; Maddalo, S. L.; Chandler, G. J.; Zimmer, M. Photophysics and Dihedral Freedom of the Chromophore in Yellow, Blue, and Green Fluorescent Protein. J. Phys. Chem. B 2009, 113 (1), 302-308.

(14) Niwa, H.; Inouye, S.; Hirano, T.; Matsuno, T.; Kojima, S.; Kubota, M.; Ohashi, M.; Tsuji, F. Chemical Nature of the Light Emitter of the Aequorea Green Fluorescent Protein. Proc. Natl. Acad. Sci. 1996, 93 (November), 13617-13622.

(15) Weber, W.; Helms, V.; McCammon, J. A.; Langhoff, P. Shedding Light on the Dark and Weakly Fluorescent States of Green Fluorescent Proteins. Proc. Natl. Acad. Sci. 1999, 96 (May), 6177-6182.

(16) Follenius-Wund, A.; Bourotte, M.; Schmitt, M.; Iyice, F.; Lami, H.; Bourguignon, J.-J.; Haiech, J.; Pigault, Cl. Fluorescent Derivatives of the GFP Chromophore Give a New Insight into the GFP Fluorescence Process. Biophys. J. 2003, 85 (3), 1839-1850.

(17) De Zitter, E.; Ridard, J.; Thédié, D.; Adam, V.; Lévy, B.; Gotthard, G.; Meervelt, L. Van; Dedecker, P.; Demachy, I.; Le, B.; Byrdin, M.; Zitter, E. De; Ridard, J.; The, D.; Gotthard, G.; Meervelt, L. Van; Dedecker, P.; Demachy, I.; Bourgeois, D.; Thédié, D.; Adam, V.; Lévy, B.; Gotthard, G.; Meervelt, L. Van; Dedecker, P.; Demachy, I. Mechanistic Investigations of Green MEos4b Reveal a Dynamic LongLived Dark State . J. Am. Chem. Soc. 2020, 142, 10978-10988.

(18) Andresen, M.; Stiel, A. C.; Trowitzsch, S.; Weber, G.; Eggeling, C.; Wahl, M. C.; Hell, S. W.; Jakobs, S. Structural Basis for Reversible Photoswitching in Dronpa. Proc. Natl. Acad. Sci. 2007, 104 (32), 13005-13009.

(19) Shinoda, H.; Lu, K.; Nakashima, R.; Shinoda, H.; Lu, K.; Nakashima, R.; Wazawa, T.; Noguchi, K.; Matsuda, T. Acid-Tolerant Reversibly Switchable Green Fluorescent Protein for Super-Resolution Imaging under Acidic Conditions Resource Acid-Tolerant Reversibly Switchable Green Fluorescent Protein for Super-Resolution Imaging under Acidic Conditions. Cell Chem. Biol. 2019, 26, 1-11.

(20) Takaba, K.; Tai, Y.; Eki, H.; Dao, H.; Hanazono, Y.; Hasegawa, K.; Miki, K.; Takeda, K. Subatomic Resolution X-Ray Structures of Green Fluorescent Protein. IUCrJ 2019, 6, 387-400.

(21) Laptenok, S. P.; Gil, A. A.; Hall, C. R.; Lukacs, A.; Iuliano, J. N.; Jones, G. A.; Greetham, G. M.; Donaldson, P.; Miyawaki, A.; Tonge, P. J.; Meech, S. R. Infrared Spectroscopy Reveals Multi-Step MultiTimescale Photoactivation in the Photoconvertible Protein Archetype Dronpa. Nat. Chem. 2018, 10, 845-852.

(22) Warren, M. M.; Kaucikas, M.; Fitzpatrick, A.; Champion, P.; Sage, J. T.; Thor, J. J. Van. Ground-State Proton Transfer in the Photoswitching Reactions of the Fluorescent Protein Dronpa. Nat. Commun. 2013, 4, 1461-1468.

(23) Christou, N.-E.; Ayala, I.; Giandoreggio-barranco, K.; Byrdin, M.; Adam, V.; Bourgeois, D.; Brutscher, B. NMR Reveals Light-Induced
Changes in the Dynamics of a Photoswitchable Fluorescent Protein. Biophys. J. 2019, 117 (11), 2087-2100.

Jensen, N. A.; Jansen, I.; Kamper, M.; Jakobs, S. Reversibly Switchable Fluorescent Proteins for RESOLFT Nanoscopy. In Nanoscale Photonic Imaging; Springer International Publishing, 2020; pp 241261.

Abbandonato, G.; Signore, G.; Nifosi, R.; Voliani, V.; Bizzarri, R.; Beltram, F. Cis - Trans Photoisomerization Properties of GFP Chromophore Analogs. Eur. Biophys. J. 2011, 40, 1205-1214.

Voliani, V.; Bizzarri, R.; Nifosı, R.; Abbruzzetti, S.; Grandi, E.; Viappiani, C.; Beltram, F. Cis - Trans Photoisomerization of Fluorescent-Protein Chromophores. J. Phys. Chem. B 2008, 112, 10714-10722.

Loria, J. P.; Rance, M.; Palmer, A. G. A Relaxation-Compensated Carr - Purcell - Meiboom - Gill Sequence for Characterizing Chemical Exchange by NMR Spectroscopy. J. Am. Chem. Soc. 1999, 121 (16), 2331-2332.

Franco, R.; Gil-Caballero, S.; Ayala, I.; Favier, A.; Brutscher, B. Probing Conformational Exchange Dynamics in a Short-Lived Protein Folding Intermediate by Real-Time Relaxation-Dispersion NMR. J. Am. Chem. Soc. 2017, 139 (3), 1065-1068.

Shinobu, A.; Agmon, N. The Hole in the Barrel : Water Exchange at the GFP Chromophore. J. Phys. Chem. 2015, 8 (119), 3464-3478.

Regmi, C. K.; Bhandari, Y. R; Gerstman, B. S.; Chapagain, P. P. Exploring the Diffusion of Molecular Oxygen in the Red Fluorescent Protein MCherry Using Explicit Oxygen Molecular Dynamics Simulations. J. Phys. Chem. B 2013, 117 (8), 2247-2253.

Mallik, R.; Udgaonkar, J. B.; Krishnamoorthy, G. Kinetics of Proton Transfer in a Green Fluorescent Protein: A Laser-Induced PH Jump Study. Proc. Indian Acad. Sci. Chem. Sci. 2003, 115 (4), 307-317.

Saxena, A. M.; Udgaonkar, J. B.; Krishnamoorthy, G. Protein Dynamics Control Proton Transfer from Bulk Solvent to Protein Interior: A Case Study with a Green Fluorescent Protein. Protein Sci. 2005, 14 (7), 1787-1799.

Agmon, N. Proton Pathways in Green Fluorescence Protein. Biophys. J. 2005, 88 (4), 2452-2461.

Shinobu, A.; Agmon, N. Proton Wire Dynamics in the Green Fluorescent Protein. J. Chem. Theory Comput. 2017, 13 (1), 353-369. Weininger, U.; Modig, K.; Akke, M. Ring Flips Revisited: 13 C Relaxation Dispersion Measurements of Aromatic Side Chain Dynamics and Activation Barriers in Basic Pancreatic Trypsin Inhibitor. Biochemistry 2014, 53, 4519-4525.

Montelione, G. T.; Wagner, G. 2D Chemical Exchange NMR Spectroscopy by Proton-Detected Heteronuclear Correlation. J Am Chem Soc. 1989, 111 (6), 3096-3098.

Woodhouse, J.; Kovacs, G. N.; Coquelle, N.; Uriarte, L. M.; Adam, V.; Barends, T. R. M.; Byrdin, M.; Mora, E. De; Doak, R. B.; Feliks, M.; Field, M.; Fieschi, F.; Guillon, V.; Jakobs, S.; Joti, Y.; Macheboeuf, P.; Motomura, K.; Nass, K.; Owada, S.; Roome, C. M.; Ruckebusch, C.; Schirò, G.; Shoeman, R. L.; Thepaut, M.; Togashi, T.; Tono, K.; Yabashi, M.; Cammarata, M.; Foucar, L.; Bourgeois, D. Photoswitching Mechanism of a Fluorescent Protein Revealed by Time-Resolved Crystallography and Transient Absorption Spectroscopy. Nat. Commun. 2020, 11, 741.

Abbruzzetti, S.; Grandi, E.; Viappiani, C.; Bologna, S.; Campanini, B.; Raboni, S.; Bettati, S.; Mozzarelli, A.; Area, P.; Molecolare, B.; Uni, V.; Volturno, V.; Nazionale, I.; Area, P. Kinetics of Acid-Induced Spectral Changes in the GFPmut2 Chromophore. J Am Chem Soc. 2005, 127 (13), 626-635.

Gayda, S.; Nienhaus, K.; Nienhaus, G. U. Mechanistic Insights into Reversible Photoactivation in Proteins of the GFP Family. Biophys. J. 2012, 103 (12), 2521-2531.

Platzer, G.; Okon, M.; Mcintosh, L. P. PH-Dependent Random Coil $1 \mathrm{H}, 13 \mathrm{C}$, and $15 \mathrm{~N}$ Chemical Shifts of the Ionizable Amino Acids : A Guide for Protein PKa Measurements. J. Biomol. NMR 2014, 60, 109129.

Pletnev, S.; Shcherbo, D.; Chudakov, D. M.; Pletneva, N.; Merzlyak, E. M.; Wlodawer, A.; Dauter, Z.; Pletnev, V. A Crystallographic Study of Bright Far-Red Fluorescent Protein MKate Reveals PH-Induced Cis-Trans Isomerization. J. Biol. Chem. 2008, 283 (43), 28980-28987. Violot, S.; Carpentier, P.; Blanchoin, L.; Bourgeois, D. Reverse PHDependence of Chromophore Protonation Explains the Large Stokes 
Shift of the Red Fluorescent Protein MKeima. J. Am. Chem. Soc. 2009, 131 (30), 10356-10357.

(43) Pace, C. N.; Fu, H.; Fryar, K. L.; Landua, J.; Trevino, S. R.; Schell, D.; Thurlkill, R. L.; Imura, S.; Scholtz, J. M.; Gajiwala, K.; Sevcik, J.; Urbanikova, L.; Myers, J. K.; Takano, K.; Hebert, E. J.; Shirley, B. A.; Grimsley, G. R. Contribution of Hydrogen Bonds to Protein Stability. Protein Sci. 2014, 23, 652-661.

(44) Gao, J.; Bisco, D. A.; Powers, E. T.; Kelly, J. W. Localized Thermodynamic Coupling between Hydrogen Bonding and Microenvironment Polarity Substantially Stabilizes Proteins. Nat. Struct. Mol. Biol. 2009, 16 (7), 684-690.

(45) Zhao, G. J.; Liu, J. Y.; Zhou, L. C.; Han, K. L. Site-Selective
Photoinduced Electron Transfer from Alcoholic Solvents to the Chromophore Facilitated by Hydrogen Bonding: A New Fluorescence Quenching Mechanism. J. Phys. Chem. B 2007, 111 (30), 8940-8945. 
SYNOPSIS TOC

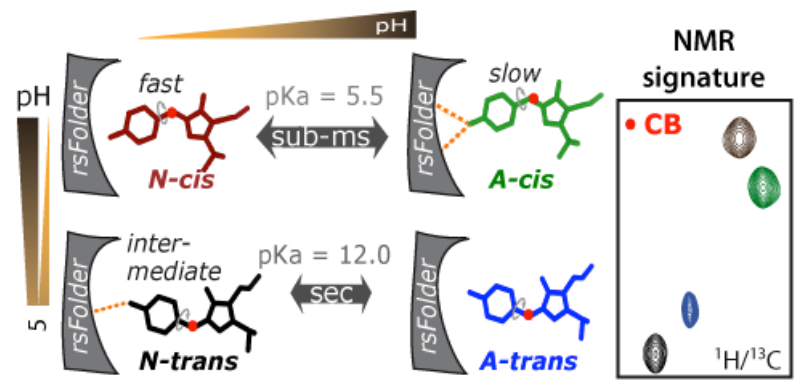

